\title{
Karl Deisseroth, Peter Hegemann, and Dieter Oesterhelt receive the 2021 Albert Lasker Basic Medical Research Award
}

$\mathbf{S}$ discovered that nerve cells conduct electricity, researchers have been working to tease out the contributions of neurons to brain function (1). Optogenetics combines optical techniques involving light and genetics to target and modulate cells. This technology has enabled scientists to control neuronal circuits in real time with precision using visible light. The 2021 Albert Lasker Basic Medical Research Award honors Karl Deisseroth of Stanford University, Peter Hegemann of Humboldt University, and Dieter Oesterhelt from the Max Planck Institute for the discovery of light-sensitive microbial proteins that can activate or deactivate individual brain cells (Figure 1). The awardees are recognized for contributing to the development of optogenetics and revolutionizing neuroscience.

\section{A purple single-celled organism} Optogenetics is a paradigm-shifting technology that started in 1971 with a purple, rod-shaped, single-celled organism and the curiosity of an enzymologist, Dieter Oesterhelt. Oesterhelt was initially interested in determining the structure of lipid protein complexes using electron microscopy. He had been preparing membrane fractions from various sources, and it wasn't too uncommon to come across pigmented fractions. But Halobacterium halobium (salinarium) was a little different. Now known as a member of the Archaeal domain, the single-celled organism $H$. halobium thrives in a variety of high-salt environments, such as the Great Salt Lake and food preparations such as salted cod. When Oesterhelt and colleagues lowered the salt concentrations in their benchtop cultures, the cell membrane dissociated into fragments, some of which were strikingly purple. Since membrane fractions from other
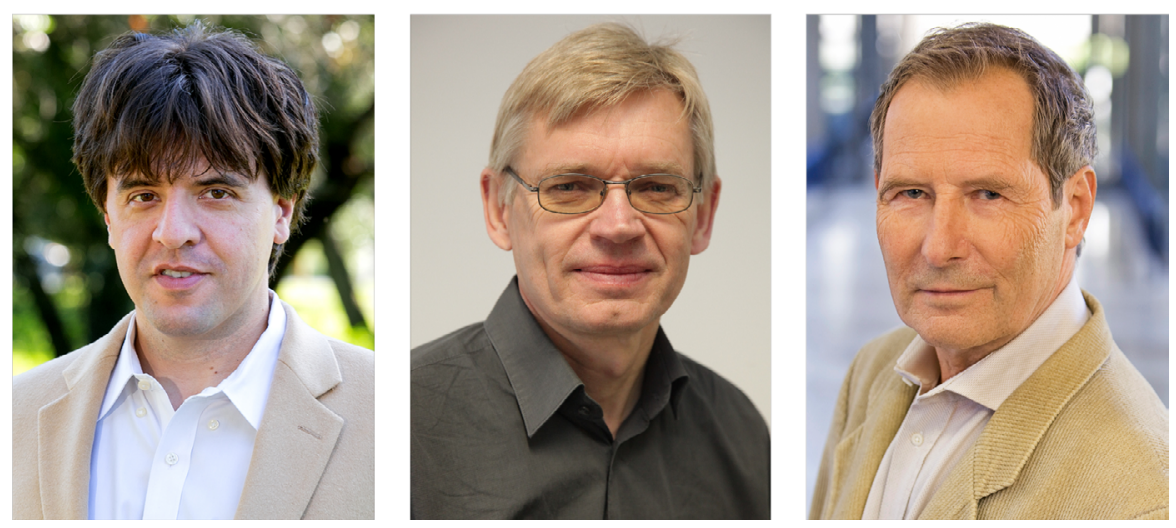

Figure 1. The recipients of the 2021 Albert Lasker Basic Medical Research Award. Karl Deisseroth (left; image credit: courtesy Lasker Foundation), Peter Hegemann (center; image credit: courtesy Lasker Foundation), and Dieter Oesterhelt (right; image credit: Max Planck Institute of Biochemistry).

organisms were red, the purple itself didn't seem too unusual. But when Oesterhelt extracted the lipids as a control experiment for his colleague, Allen Blaurock, the purple shifted dramatically to yellow. "This astonished me completely as a chemist because it seemed impossible. But nobody else was interested in this color change. So I started to analyze the pigment."

In the lab of Walther Stoeckenius, Oesterhelt pushed forward. He grew H. halobium and isolated the purple membranes, then purified the protein. He made a point of "insisting" on performing mass spectrophotometry. Strikingly, the protein fraction contained only one single protein, which harbored retinal (2). At the time, retinal was known to couple with visual rhodopsins in protein complexes of higher animals. The day that Oesterhelt held the mass spectrum data with retinal in his hands, he knew it would be his scientific topic for research. It was near midnight when he got home and told his wife, "If this holds true, then I made a discovery." It was the only retinal protein complex described outside the highly structured retina. Oesterhelt hypothesized that the protein in the purple membrane acted as a photoreceptor and called it bacteriorhodopsin $(2,3)$.

Oesterhelt characterized the purple membranes in a series of chemistry experiments that relied largely on a simple $\mathrm{pH}$ meter. When he exposed the cell suspension to light, he had a surprise. "When I first did the experiment, I turned on the light at the highest intensity and the $\mathrm{pH}$ meter went off scale." The result indicated that protons were moving from one side of the membrane to the other. Since the membrane patches contained only one protein, Oesterhelt proposed that bacteriorhodopsin itself was a lightdriven proton pump (3).

However, the breakthrough for Oesterhelt was not yet recognized or appreciated by the scientific community. The proposal that the bacteriorhodopsin acted as a light-driven proton pump created resistance in the rhodopsin field. Oesterhelt felt that even if his finding were true, no one might believe that it was of any importance. "It was my breakthrough in the sense that I knew that I would definitely know about the function of the molecule in the cell later on. You could call that a breakthrough because I knew what would be my scientific topic for independent research work." 


\section{Phototaxis and photocurrents}

The question remained: how does a single cell see? What was it about a lightactivated protein that could create optical behavior? As one of Oesterhelt's students, Peter Hegemann had been studying the light-activated chloride pump halorhodopsin when he came across a Nature paper from Ken Foster's lab. The paper suggested that an alga known as Chlamydomonas represented a model for studying photoreceptor cells (4). Chlamydomonas, an organism normally found in fresh water and temperate soil habitats, was the subject of interest because it had a light-sensing eyespot. Moreover, it used the pigmented eyespot to coordinate the movement of two flagella, which propelled the organism toward light. The cultures grew easily in the lab, and Foster's group had remarkably acquired a blind mutant (4).

"So I changed my plans and decided to go to Ken Foster's lab," Hegemann recounted. "He [Foster] was of the opinion that the photoreceptor for phototaxis of the unicellular green alga Chlamydomonas was a rhodopsin. And he also did one more step. He demonstrated that phototaxis could be recovered in a blind Chlamydomonas mutant by the addition of retinal."

After spending a year in Syracuse, New York, in the Foster lab, Hegemann returned to the Max Planck Institute of Biochemistry in Munich, Germany. As a researcher with an independent position, Oesterhelt encouraged Hegemann to work on a new project. "My plan was to purify the rhodopsin from this Chlamydomonas creature, and I thought I could do it in a year. But it took me 15 years, actually."

Initial genetic and biochemical approaches in Chlamydomonas reinhardtii were challenging because the organism had two channelrhodopsin genes and ten rhodopsin proteins $(5,6)$. In 2002, after many biochemical approaches, Hegemann and colleagues identified channelrhodopsin-1 as a light-gated proton channel (5). Channelrhodopsin-2 was described a year later (6).

While the research group worked to identify the photoreceptors as channelrhodopsin-1 and -2, they also characterized the endogenous electrical responses in Chlamydomonas. A graduate student in Hegemann's lab, Hartmann Harz, identified photocurrents that were incredibly fast, much faster than photocurrents from humans or Drosophila (7). Strikingly, the photocurrents initiated flagellar currents that were similar to action potentials in neurons. The group proposed that the rhodopsin in the eyespot and the channel were a single protein (8).

The researchers expressed the channelrhodopsin cDNA in Xenopus laevis oocytes, which was the prevailing model for studying exogenous channels. When the large eggs were exposed to light, the team observed electrical responses as expected. However, because the surface area of a $X$. laevis oocyte is much greater than that of a one-micrometer diameter Chlamydomonas eyespot, many more proteins were expressed and the responses were 100,000 times larger than those seen in the early studies $(6,7)$. These experiments firmly established channelrhodopsin as a light-sensitive single proton channel with fast currents.

Soon researchers began expressing channelrhodopsins in mammalian cells (6), which encouraged the neuroscience community to apply it in neurons. The first observations in neurons were made by Karl Deisseroth in 2005 (9).

\section{The systems level}

Deisseroth was trained as neuroscientist and psychiatrist, but also has a strong background in molecular biology and biochemistry. As a new professor at Stanford, he remained deeply influenced by chemical tools. After his first channelrhodopsin experiments, Deisseroth reached out to Hegemann. The two clicked right away. Deisseroth recounted, "From the very beginning we had a series of conversations. We would say, 'Hey, let's make fundamentally new kinds of channelrhodopsins, let's make different color-activated versions, let's make one with totally different kinetics that's much faster, let's make another one that's much slower. Let's redesign them for different ion selectivity. Let's do all these things together." After acquiring high-resolution crystal structures of channelrhodopsin (10), the team engineered high-efficiency, color-tuned, cation-conducting channelrhodopsins that could activate cells $(11,12)$, and then they created a robust anion-conducting channelrhodopsin that could inhibit cells $(13,14)$.

Beyond chemistry, Deisseroth had a systems level interest. "In psychiatry, we have medications that help people, we have brain stimulation approaches that help people, but they're not as specific as we'd like, and they're not as grounded in deep scientific understanding as we'd like." Historically, neuroscientists had stimulated neural tissue with electrodes or medications, but those strategies weren't precise. After years of developing light-sensitive protein and related technologies, Deisseroth was poised to probe neuronal circuits with light.

Initially people were skeptical. "A lot of people didn't believe, and I think rightly so," Deisseroth said. The initial experiments to activate neurons in 2005 were performed in flat culture dishes using a lentiviral gene-delivery system (9). It didn't seem possible to precisely target neural circuits in vivo using light as a switch. "Beginning in 2007, we showed through multiple different approaches that we could use an optical interface to control moving, feeding, and behavior in freely moving mice, and that was a huge step." Working initially in rats, Deisseroth's group injected lentiviral genetic constructs that targeted channelrhodopsin-2 to excitatory neurons using a CaMKII promoter. A thin optical fiber delivered light to the cortex, and pulses of blue light triggered the whiskers to twitch. Because the experiments were controlled, the group was able to show temporal control of targeted neuronal subtypes (15).

Other studies followed using next-generation channelrhodopsins and other behavioral systems. Deisseroth's research has a focus on motivation and survival drives. He has explored circuits involved with social interaction, fear and anxiety, and thirst $(16,17,18)$. Deisseroth has been struck by how cleanly resolved these brain and behavioral states can be in mammals. "We can access virtually every single cell in a zebrafish brain now. We've developed ever more wide-field optics that let us observe and control the light over wider and wider swaths of brain regions or even all across the cortex in mice now. There is the prospect of moving toward completeness at the single-cell level. And that's pretty exciting," Deisseroth reflected.

\section{The collaboration continues}

Recently, optogenetics techniques were used to restore some aspects of vision in a patient with retinal degeneration (19). While other studies seek to apply the methods, for example, to treat seizures in epi- 
lepsy (20), Deisseroth and Hegemann are working to create more sensitive optogenetic tools, using infrared light to penetrate the brain and creating light-activated enzymes to investigate cells beyond neurons.

When Luigi Galvani described what he termed "animal electricity," he noted his goal of "bringing to light whatever might be concealed in the phenomenon" (1). The 2021 Albert Lasker Basic Medical Research Award recognizes the important role the work of these awardees has played in lighting the way toward optogenetic manipulation of specific neuronal circuits. In their discussion with the JCI, Oesterhelt, Hegemann, and Deisseroth humbly acknowledged the recognition of their work with this award, and each scientist made a point of recognizing the hundreds of talented students, colleagues, and researchers that contributed to developing optogenetics. Moreover, all three also emphasized the importance of pursuing basic research. Deisseroth told the JCI, "This is a great example of how truly undirected basic research has really helped clinical medicine. Dieter Oesterhelt, 50 years ago, was visiting UCSF and discovered the first microbial rhodopsin, bacteriorhodopsin. And needless to say, he was not thinking about psychiatry or anxiety, at least in terms of that his work would be relevant to those fields. It's just a great example of the value of pure basic science."

\section{Lisa R. Conti}

1. Galvani L, Aldini G, eds. Commentary on the Effect of Electricity on Muscular Motion. E. Licht; 1953.

2. Oesterhelt D, Stoeckenius W. Rhodopsin-like protein from the purple membrane of Halobacterium halobium. Nat New Biol. 1971;233(39):149-152.

3. Oesterhelt D, Stoeckenius W. Functions of a new photoreceptor membrane. Proc Natl Acad Sci US A. 1973;70(10):2853-2857.

4. Foster KW, et al. A rhodopsin is the functional photoreceptor for phototaxis in the unicellular eukaryote Chlamydomonas. Nature. 1984;311(5988):756-759.

5. Nagel G, et al. Channelrhodopsin-1: a light-gated proton channel in green algae. Science. 2002;296(5577):2395-2398.

6. Nagel G, et al. Channelrhodopsin-2, a directly light-gated cation-selective membrane channel. Proc Natl Acad Sci U S A. 2003;100(24):13940-13945

7. Harz H, Hegemann P. Rhodopsin-regulated calcium currents in Chlamydomonas. Nature. 1991;351:489-491.

8. Braun FJ, Hegemann P. Two light-activated conductances in the eye of the green alga Volvox carteri. Biophys J. 1999;76(9):1668-1678.

9. Boyden ES, et al. Millisecond-timescale, genetically targeted optical control of neural activity.
Nat Neurosci. 2005;8(9):1263-1268.

10. Kato HE, et al. Crystal structure of the channelrhodopsin light-gated cation channel. Nature. 2012;482(7385):369-374.

11. Yizhar O, et al. Neocortical excitation/inhibition balance in information processing and social dysfunction. Nature. 2011;477(7363):171-178.

12. Prigge $\mathrm{M}$, et al. Color-tuned channelrhodopsins for multiwavelength optogenetics. J Biol Chem. 2012;287(6182):31804-31812.

13. Berndt A, et al. Structure-guided transformation of channelrhodopsin into a light-activated chloride channel. Science. 2014;344(6182):420-424.

14. Berndt A, et al. Structural foundations of optogenetics: determinants of channelrhodopsin ion selectivity. Proc Natl Acad Sci U S A. 2016;113(7338):822-829.

15. Aravanis AM, et al. An optical neural interface: in vivo control of rodent motor cortex with integrated fiberoptic and optogenetic technology. J Neural Eng. 2007;4(3):S143-S156.

16. Gunaydin LA, et al. Natural neural projection dynamics underlying social behavior. Cell. 2014;157(7):1535-1551.

17. Tye KM, et al. Amygdala circuitry mediating reversible and bidirectional control of anxiety. Nature. 2011;471(7338):358-362.

18. Allen WE, et al. Thirst-associated preoptic neurons encode an aversive motivational drive. Science. 2017;357(6356):1149-1155.

19. Sahel JA, et al. Partial recovery of visual function in a blind patient after optogenetic therapy. Nat Med. 2021;27(7):1223-1229.

20. Chen R, et al. Deep brain optogenetics without intracranial surgery. Nat Biotechnol. 2021;39(2):161-164. 